\title{
Pengaruh Corporate Governance Dan Kualitas Audit Terhadap Pencegahan Kecurangan
}

\author{
Sarah Fadlilah Sanusi, Sutrisno, Darmo H Suwiryo \\ Program Studi Akuntansi, Fakultas Ekonomi \\ Universitas Muhammadiyah Sukabumi
}

J1. R. Syamsudin, S.H, No. 50, Cikole, Kota Sukabumi, Jawa Barat, Indonesia

\begin{abstract}
The purpose of this study is to examine the effect of good corporate governance and audit quality on fraud prevention. The research method used is quantitative method is a method of research data in the form of numbers and analysis using statistics. The population used is all employees at CV. Agung Mas Motor, Sukabumi City, amounting to 35 people. The sample is determined by nonprobability sampling with a saturated sampling technique. Sources of data used in the form of data collection carried out through the distribution of questionnaires that have been tested for validity and reliability. Data analysis techniques use hypothesis testing using SPSS 24. The results of research and data processing show that Corporate Governance has a significant effect on Fraud Prevention and Audit Quality that have no significant effect on Fraud Prevention. The results of simultaneous test between Corporate Governance and Quality Audit have a significant effect toward fraun prevention.
\end{abstract}

Keywords: Corporate Governance, Audit Quality, Fraud Prevention.

\begin{abstract}
ABSTRAK
Tujuan dari penelitian ini adalah untuk menguji pengaruh good corporate governance dan kualitas audit terhadap pencegahan penipuan. Metode penelitian yang digunakan adalah metode kuantitatif dan analisis menggunakan statistik. Populasi yang digunakan adalah semua karyawan di CV. Agung Mas Motor, Kota Sukabumi, berjumlah 35 orang. Sampel ditentukan oleh nonprobability sampling dengan teknik sampling jenuh. Sumber data yang digunakan dalam bentuk pengumpulan data dilakukan melalui penyebaran kuesioner yang telah diuji validitas dan reliabilitasnya. Teknik analisis data untuk pengujian hipotesis menggunakan SPSS 24. Hasil penelitian dan pengolahan data menunjukkan bahwa Tata Kelola Perusahaan memiliki pengaruh signifikan terhadap Pencegahan Penipuan sementara Kualitas Audit tidak memiliki pengaruh signifikan terhadap Pencegahan Penipuan. Hasil uji simultan antara Tata Kelola Perusahaan dan Audit Kualitas memiliki pengaruh yang signifikan terhadap pencegahan kecurangan.
\end{abstract}

Keywords: Corporate Governance, Kualitas Audit, Pencegahan Kecurangan.

\section{PENDAHULUAN}

Kelangsungan usaha akan terganggu atau bisa saja berhenti jika kecurangan dibiarkan tanpa adanya upaya atau pencegahan yang dilakukan untuk mencegah ataupun mengungkap adanya tindak pidana kecurangan. Beberapa bentuk fraud diantaranya adalah pencucian uang (money laundering), dan gratifikasi. Korupsi (corruption) merupakan salah satu bentuk fraud yang terjadi pada organisasi sektor publik di Indonesia yang kemudian menjadi trending topic saat ini. Audit dirancang untuk memberikan keyakinan bahwa laporan keuangan tidak dipengaruhi oleh salah saji (misstatement) material dan juga memberikan keyakinan yang memumpuni atas akuntabilitas manajemen atas aktiva perusahaan. Salah saji itu terdiri dari dua 
macam yaitu kekeliruan (error) dan kecurangan (fraud). Kecurangan terjadi karena ada faktor penyebab yang tidak terlepas dari konsep segitiga kecurangan (fraud triangle) yaitu tekanan (pressure), kesempatan (opportunity) dan rasionalisasi (rationalization).

Untuk mengatasi potensi timbulnya kecurangan, maka corporate governance atau tata kelola perusahaan sangat dibutuhkan oleh suatu perusahaan karena merupakan bagian yang sangat penting. Amin Widjaja Tunggal (2012:59) mengemukakan bahwa terdapat beberapa tata kelola untuk mencegah kecurangan (fraud) diantaranya menciptakan budaya jujur dan etika yang tinggi, tanggung jawab manajemen untuk mengevaluasi pencegahan fraud dan pengawasan oleh komite audit.

Menurut Tjun Tjun et al dalam Moch (2012) Kualitas audit merupakan segala kemungkinan (probability) dimana auditor pada saat mengambil laporan keuangan klien dapat menemukan pelanggaran yang terjadi dalam sistem akuntansi klien dan melaporkannya dalam laporan keuangan auditan, dimana dalam melaksanakan tugasnya tersebut auditor berpedoman pada standar auditing dan kode etik akuntan publik yang relevan. Dalam menghadapi kecurangan seorang auditor pun harus siap untuk melaporkan hal tersebut walaupun itu ulah pegawai atau bahkan atasannya sendiri, agar kualitas audit yang didapat baik.

Kecurangan umumnya terjadi karena adanya tekanan (preasure) untuk melakukan penyelewengan atau dorongan untuk memanfaatkan kesempatan (opportunity) yang ada dan adanya pembenaran terhadap tindakan tersebut. Dalam istilah sehari-hari fraud dikenal seperti pencurian, pemerasan, penggelapan, pemalsuan, dan lain-lain. Karyono (2013:1), Fraud merupakan tindakan melawan hukum yang merugikan suatu entitas/organisasi dan menguntungkan pelakunya. Jadi kecurangan adalah sekumpulan tindakan yang tidak diizinkan dan melanggar hukum yang ditandai dengan adanya unsur kecurangan yang disengaja.

Menurut Kepala Cabang bapakWinston Johanly kecurangan yang dila kukan oleh bagianservis mekanik/karyawan melakukan kecurangan dengan $\mathrm{m}$ enjual barang dari luar tetapi mengatasnamakan CV.Agung Mas Motor dan harganya dinaikkan. Sehingga perusahaan dirugikan dalam pemasukan dan nama baik menjadi jelek. Kasus ini terbongkar setalah dilakukan nya audit internal yang dilakukan oleh bapak Tedi, dari hasil audit ditemukan ketidaksesuaian antara unit yang terjual dan kas yang diterima. Pada tahun 2017 kecurangan yang dilakukan oleh karyawan perusahaan bagian sales lapangan, konsumen membayar dana sebesar 3.000.000 tetapi tidak disetorkan pada perusahaan, menipulasi data nasabah (KTP/data fiktif). Kecurangan yang terjadi pada CV.Agung Mas Motor, diduga karena pengawasan yang kurang baik dari atasan, gaji yang tidak sesuai atau adanya peluang untuk melakukan hal tersebut yang tentunya merugikan perusahaan.

Kasus diatas adalah tindak kecurangan yang mengharuskan tata kelola perusahaan yang baik diterapkan terhadap karyawan maupun atasan diperusahaan tersebut guna mengarahkan dan mengendalikan perusahaan untuk mencegah timbulnya kecurangan atau kesalahan dari pihak menejemen yang dapat merugikan komisaris, investor, kreditur, pemerintah dan masyarakat serta pihak-pihak berkepentingan lainnya. Agar potensi kecurangan tersebut sedikit berkurang yaitu dengan menerapkan prinsip-prinsip Good Corporate Governance dan memperketat pengauditan agar hasil dari kualitas audit mendapatkan hasil yang maksimal dan adanya perubahan dalam perusahaan. Kualitas audit menjadi harapan dari pengguna 
jasa audit terutama publik atau pemegang saham yang menaruh harapan bahwa laporan keuangan yang telah di audit tentunya merupakan laporan keuangan yang bebas dari salah saji material, baik yang disebabkan oleh kekeliruan atau kecurangan.

\section{TINJAUAN PUSTAKA \\ Good Corporate Governance}

Menurut Forum for Corporate Governance in Indonesia (FCGI), Good Governance adalah seperangkat peraturan yang menetapkan hubungan antara pemegang saham, pengurus, kreditur, pemerintah, karyawan serta para pemegang kepentingan intern dan ekstern lainnya sehubungan dengan hak-hak dan kewajiban mereka, atau dapat dikatakan sebagai suatu sistem yang mengarahkan dan mengendalikan perusahaan (Sari dkk, 2015). Bank Indonesia menjelaskan bahwa Good Corporate Governance merupakan tata kelola bank melalui penerapan beberapa prinsip, yaitu:

a. Transparency (Keterbukaan), yaitu prinsip yang menjunjung keterbukaan dalam mengungkapkan segala informasi yang material secara memadai, tepat waktu dan akurat serta keterbukaan perusahaan dalam pengambilan keputusan.

b. Accountability (Akuntabilitas), yaitu prinsip yang menuntut adanya kejelasan fungsi atau pemisahan tugas dan pelaksanaan tanggung jawab setiap bagian dalam perusahaan sehingga perusahaan dapat dikelola dengan baik.

c. Responsibility (Pertanggungjawaban), yaitu prinsip yang mengharuskan agar pengelolaan perusahaan sesuai dan patuh terhadap prinsip korporasi yang sehat dan sesuai dengan peraturan dan perundang-undangan yang berlaku.

d. Independency (Kemandirian), yaitu prinsip yang mengharuskan pengelolaan perusahaan secara profesional tanpa benturan kepentingan atau tekanan dari pihak manapun.

e. Fairness (Kesetaraan dan Kewajaran), yaitu prinsip yang menuntut pemenuhan hak-hak pemegang saham secara adil dan setara sesuai dengan perjanjian yang disepakati dan sesuai dengan peraturan perundangundangan yang berlaku.

\section{Kecurangan (Fraud)}

Menurut International Standards on Auditing (ISA) seksi 240 tentang tanggung jawab auditor untuk mempertimbangan fraud dalam audit laporan keuangan, fraud didefinisikan sebagai perbuatan yang disengaja oleh seseorang atau beberapa orang diantara manajemen, TCWG (Those Charge With Governance), pegawai, atau pihak ketiga, dengan menipu untuk memperoleh keuntungan yang tidak dapat dibenarkan atau yang tidak sah/melawan hukum (Tuanakotta, 2014:308). Fraud dapat terjadi karena beberapa faktor. Albrecht et al. (2012:34) menjelaskan bahwa fraud dapat terjadi karena 3 kondisi (fraud triangle), yaitu: 


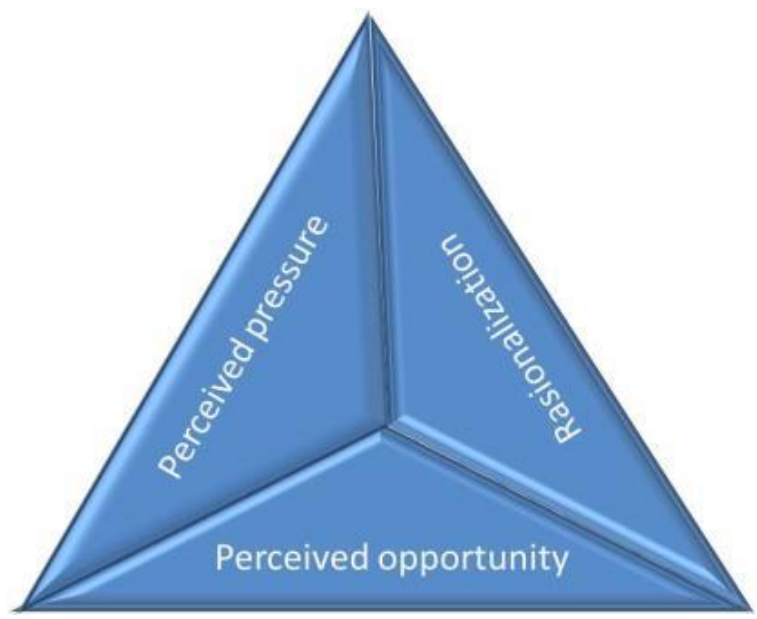

Sumber: Albrecht et al. (2012)

Gambar 2.1. Fraud Triangle

Tekanan (Perceived pressure) akan menyebabkan situasi dimana seseorang atau sekelompok orang terdorong untuk melakukan fraud. Tekanan ini bisa disebabkan karena sifat serakah, kebutuhan keluarga yang harus segera terpenuhi, ketidakpuasan karyawan terhadap dunia kerjanya, dll. Motif selanjutnya adalah peluang (Perceived opportunity). Peluang adalah kondisi dimana seseorang memiliki kesempatan untuk melakukan fraud. Biasanya peluang ini muncul karena lemahnya sistem pengendalian internal perusahaan. Peluang juga bisa berawal dari tekanan atau dorongan dari dalam diri seseorang sehingga mencari peluang untuk melaksanakan kecurangan tersebut.

Motif yang terakhir adalah rasionalisasi, yaitu pikiran seseorang yang membenarkan tindakan fraud yang dilakukannya. Pikiran ini biasanya muncul karena ia melihat orang lain dalam organisasinya melakukan fraud namun mereka tidak mendapat hukuman dari perbuatannya itu. Selain itu, pikiran ini juga dapat muncul karena menurut mereka, aset yang mereka ambil adalah memang hak mereka karena mereka telah memberikan kontribusi atau jasa bagi perusahaan.

\section{Pencegahan Fraud (Fraud Prevention)}

Menurut Sudarmo dkk (2009:37), Pencegahan fraud adalah upaya terintegrasi yang dilakukan agar penyebab terjadinya fraud (fraud triangle) dapat ditekan yaitu melalui upaya dibawah ini:

a. Meminimalisir adanya peluang (opportunity) untuk melakukan fraud.

b. Menurunkan tekanan (pressure) pada setiap organ perusahaan agar ia mampu memenuhi kebutuhannya.

c. Mengeliminasi munculnya rasa rasionalisasi (rasionalization) yang memunculkan alasan pembenaran atas tindakan kecurangan yang dilakukan.

\section{Hipotesis}

Berdasarkan uraian diatas maka dapat disusun hipotesis sebagai berikut:

H1 : Good corporate governance berpengaruh positif terhadap pencegahan fraud

$\mathrm{H} 2$ : Kualitas audit berpengaruh positif terhadap pencegahan fraud

H3 : Good corporate governance dan Kualitas audit berpengaruh positif terhadap pencegahan fraud 


\section{METODE}

Penelitian ini dilakukan di CV. Agung Mas Motor yang beralamat di Jln. Jendral Sudirman No.43 Kota Sukabumi. Dengan alasan karena pada setiap perusahaan memiliki tujuan untuk dicapai, salah satunya untuk memperoleh keuntungan yang maksimal. Penyampelan menggunakan teknik non probability sampling. Sampling dari penelitian ini adalah seluruh karyawan di perusahaan yang berjumlah 35 orang. Data dikumpulkan dengan mengisi kuisioner.

\section{TEKNIK ANALISIS DATA}

Analisis data dilakukan dengan menggunakan SPSS versi 24 for windows. Spss adalah program komputer yang dipakai untuk analisis statistika. Dengan menggunakan uji validitas, uji reliabilitas, uji asumsi klasik, uji normalitas data, uji multikolinieritas, uji heteroskedastisitas, uji regresi linear berganda, uji t dan uji f, serta uji koefisien determinasi.

\section{HASIL DAN PEMBAHASAN}

Tabel 1 Berdasarkan tabel uji t yang telah dilakukan pada variabel Corporate Governance dengan kriteria pengujian taraf signifikan $\alpha=0,05, \mathrm{df}=\mathrm{n}-\mathrm{k}-1$, maka $\mathrm{df}=35-2-1=32$, sehingga diperoleh $t_{\text {tabel }}$ sebesar 2,036.

\section{Hasil Uji Parsial (T) Corporate Governance}

\begin{tabular}{|c|c|c|c|c|c|c|}
\hline \multicolumn{7}{|c|}{ Coefficients $^{\text {a }}$} \\
\hline \multirow{2}{*}{\multicolumn{2}{|c|}{ Model }} & \multicolumn{2}{|c|}{ Unstandardized Coefficients } & \multirow{2}{*}{$\begin{array}{c}\text { Standardized } \\
\text { Coefficients } \\
\text { Beta }\end{array}$} & \multirow[b]{2}{*}{$\mathrm{t}$} & \multirow[b]{2}{*}{ Sig. } \\
\hline & & $\mathrm{B}$ & Std. Error & & & \\
\hline \multirow[t]{2}{*}{1} & (Constant) & 15,541 & 7,212 & & 2,155 &, 039 \\
\hline & TOTALX1 & 472 & 140 & ,531 & 3,368 &, 002 \\
\hline
\end{tabular}

a. Dependent Variable: TOTALY

Sumber: IBM SPSS 24, 2019

Tabel 2 Berdasarkan tabel uji t yang telah dilakukan pada variabel Kualitas Audit dengan kriteria pengujian taraf signifikan $\alpha=0,05, \mathrm{df}=\mathrm{n}-\mathrm{k}-1$, maka $\mathrm{df}=35$ $2-1=32$, sehingga diperoleh $t_{\text {tabel }}$ sebesar 2,036. Berdasarkan tabel diatas diatas menunjukan bahwa thitung dari variabel Kualitas Audit $\left(\mathrm{X}_{2}\right)$ sebesar 0,380 dengan tingkat signifikan 0,707. Nilai thitung $<\mathrm{t}_{\text {tabel }}$ 2,036, maka Ho diterima dan Ha ditolak, artinya bahwa secara parsial variabel independen tidak berpengaruh terhadap variabel dependen, dan nilai signifikannya (sig) 0,707>0,05, maka dapat disimpulkan bahwa Kualitas Audit $\left(\mathrm{X}_{2}\right)$ tidak berpengaruh signifikan terhadap Pencegahan kecurangan (Y).

Hasil Uji Parsial (T) Kualitas Audit

\begin{tabular}{|c|c|c|c|c|c|c|}
\hline \multicolumn{7}{|c|}{ Coefficients $^{\mathrm{a}}$} \\
\hline & & \multicolumn{2}{|c|}{ Unstandardized Coefficients } & $\begin{array}{l}\text { Standardized } \\
\text { Coefficients }\end{array}$ & \multirow[b]{2}{*}{$\mathrm{t}$} & \multirow[b]{2}{*}{ Sig. } \\
\hline \multicolumn{2}{|c|}{ Model } & B & Std. Error & Beta & & \\
\hline \multirow[t]{2}{*}{1} & (Constant) & 15,541 & 7,212 & & 2,155 & 039 \\
\hline & TOTALX2 &, 046 &, 122 &, 060 &, 380 & ,707 \\
\hline
\end{tabular}

a. Dependent Variable: TOTALY

Sumber: Output IBM SPSS 24, 2019 
Tabel 3 Berdasarkan tabel dibawah ini menunjukan bahwa $F_{\text {hitung }} 5.841>$ $F_{\text {tabel }}$ 3,29 dengan signifikan $0,007<0,05$ maka hipotesis Ha diterima dan Ho ditolak, yaitu secara simultan (bersama - sama) variabel independen berpengaruh signifikan terhadap variabel dependen.

\section{Hasil Uji Simultan (F)}

\begin{tabular}{l|l|r|r|r|r|r}
\hline \multicolumn{7}{c}{ ANOVA $^{\mathbf{a}}$} \\
\hline \multicolumn{1}{l|}{ Model } & Sum of Squares & Df & Mean Square & F & Sig. \\
\hline \multirow{2}{*}{1} & Regression & 46,425 & 2 & 23,212 & 5,841 &, $007^{\mathrm{b}}$ \\
\cline { 2 - 8 } & Residual & 127,175 & 32 & 3,974 & & \\
\cline { 2 - 8 } & Total & 173,600 & 34 & & & \\
\hline
\end{tabular}

a. Dependent Variable: TOTALY

b. Predictors: (Constant), TOTALX2, TOTALX1

Sumber: Output IBM SPSS 24,2019

Tabel 4 Berdasarkan tabel dibawah ini maka dapat diketahui bahwa nilai koefisien determinasi $(\mathrm{Kd})$ sebesar 0,517 ini sama dengan hasil menggunakan rumus $\mathrm{Kd}=\mathrm{R}^{2} \times 100 \%=\left(0,517^{2} \times 100 \%\right)=26,7 \%$ maka dapat disimpulkan bahwa Corporate Governance, dan Kualitas Audit berpengaruh sebesar 26,7\% terhadap pencegahan kecurangan, dan sisanya $73,3 \%$ dipengaruhi dari faktor - faktor lain yang tidak diteliti dalam penelitian ini.

\section{Koefisien Determinasi}

\begin{tabular}{l|c|c|c|c}
\hline \multicolumn{5}{c}{ Model Summary } \\
\hline Model & $\mathrm{R}$ & $\mathrm{R}$ Square & $\begin{array}{c}\text { Adjusted R } \\
\text { Square }\end{array}$ & Std. Error of the Estimate \\
\hline 1 &, $517^{\mathrm{a}}$ &, 267 &, 222 & 1,994 \\
\hline a. Predictors: (Constant), TOTALX2, TOTALX1 \\
Sumber: Output IBM SPSS 24,2019
\end{tabular}

\section{PEMBAHASAN}

\section{Pengaruh Corporate Governance Terhadap Pencegahan Kecurangan}

Corporate Governance berpengaruh terhadap pencegahan kecurangan, dimana perusaan harus menerapkan prinsip-prinsip GCG diperusahaan dengan keadilan, transparansi, akuntabilitas, dan pertanggungjawaban. Penelitian ini sejalan dengan Novia Rizky Amelia R (2017) Audit internal dan Good Corporate Governance secara signifikan berpengaruh terhadap pencegahan kecurangan.

\section{Pengaruh Kualitas Audit Terhadap Pencegahan Kecurangan}

Penelitian ini bertolak belakang dengan hasil penelitian yang dilakukan oleh Mia Monika (2016) yang menunjukan bahwa Kualitas auditor internal memiliki pengaruh signifikan dengan arah negatif terhadap deteksi kecurangan dan pengaruh signifikan asimetri informasi dengan arah positif terhadap deteksi kecurangan. Kualitas audit tidak berpengaruh disebabkan oleh faktor-faktor lain, misalnya seperti yang terjadi di CV. Agung Mas terdapat karyawan yang masih mempunyai double job, dimana 1 orang karyawan diberikan tanggung jawab untuk menyelesaikan tugas seorang finance (keuangan) dan audit internal. Hal tersebut seharusnya tidak dikehendaki, dimana seorang finance merangkap sebagai audit 
internal tidak menutup kemungkinan dia akan melakukan kecurangan dikarenakan dia yang melakukan penyusunan keuangan perusahaan, melakukan transaksi keuangan, melakukan penginputan semua transaksi keuangan kedalam program, dan lain-lain. Sedangkan audit internal memiliki tugas untuk melaksanakan pengauditan dan melaporkannya dalam bentuk laporan audit, serta melakukan monitoring dan evaluasi hasil audit internal.

\section{Pengaruh Corporate Governance dan Kualitas Audit Terhadap PencegahanKecurangan}

Tindakan kecurangan dapat diminimumkan dengan penerapan Corporate Governance. Secara umum terdapat 3 alat pencegahan kecurangan, yaitu: tata kelola perusahaan, pimpinan organisasi yang baik (bersih), dan penerapan pengendalian internal. Cattrysee (2002) dalam Gusnardi (2009:134). De Angelo (2016:83) menyatakan bahwa kualitas audit merupakan joint probability dan pendeteksian juga pelaporan kesalahan laporan keuangan yang secara parsial tergantung pada independensi auditornya.

\section{SIMPULAN}

Corporate Governance berpengaruh signifikan terhadap pencegahan kecurangan. Dimana nilai $t_{\text {hitung }}$ dari variabel Corporate Governance $\left(\mathrm{X}_{1}\right)$ sebesar 3,368 dengan tingkat signifikan 0,002. Nilai $t_{\text {hitung }} 3,368>t_{\text {tabel }} 2,036$ maka Ha diterima dan Ho ditolak, artinya bahwa secara parsial variabel independen berpengaruh terhadap variabel dependen, dan nilai signifikannya (sig) 0,002>0,05. Kualitas Audit tidak berpengaruh signifikan terhadap pencegahan kecurangan. Dengan nilai thitung $<\mathrm{t}_{\text {tabel }} 2,036$, maka Ho diterima dan Ha ditolak, artinya bahwa secara parsial variabel independen tidak berpengaruh terhadap variabel dependen, dan nilai signifikannya (sig) 0,707>0,05. Corporate Governance dan kualitas audit, secara simultan berpengaruh signifikan terhadap pencegahan kecurangan. Dengan nilai $F_{\text {hitung }} 5.841>\mathrm{F}_{\text {tabel }}$ 3,29 dengan signifikan 0,007 $<0,05$ maka hipotesis $\mathrm{Ha}$ diterima dan Ho ditolak, yaitu secara simultan (bersama - sama) variabel independen berpengaruh signifikan terhadap variabel dependen. Dan sisanya sebesar $96,7 \%$ dipengaruhi oleh faktor lain yang tidak diteliti.

\section{DAFTAR PUSTAKA}

Albrecht et al. 2012. Fraud Examination : Fourth Edition. South-Western: Cengage Learning.

Adrian, Sutedi. 2012. Good Corporate Governance. Jakarta: Sinar Grafika.

Ghozali, Imam. 2013. Aplikasi Analisis Multivariate Dengan Program SPSS. Semarang: Badan Penerbit Universitas Diponegoro.

Hamdani. 2016. Good Corporate Governance, Tinjauan Etika dalam Praktek Bisnis. Jakarta: Mitra Wacana Media.

Karyono. 2013. Forensic Froud. Yogyakarta: Andi.

Kovinna, Fransiska dan Betri, 2014. Pengaruh Independensi, Kerja,Kompetensi dan Etika Auditor terhadap Kualitas Audit (studi kasus pada Kantor Akuntan Publik diKota Palembang). Palembang. STIE MDP.

Kumaat, Valery G. 2011. Internal Audit. Jakarta: Erlangga.

Mathius. 2014. Kualitas Audit dan Pengukurannya. Bandung: Alfabeta.

Melai R. 2017. Pengaruh Kualitas Auditor dan Corporate Governance terhadap Manajemen Laba. Jurnal: Universitas Muhammadiyah Magelang. 
Monika, Mia. 2016. Pengaruh Kualitas Audit Internal dan Asimetri Informasi terhadap Pendeteksian Kecurangan (fraud). Jurnal: Universitas Komputer Indonesia.

Moch. 2016. Pengaruh Independensi dan Profesionalisme Auditor terhadap Kualitas Audit. Skripsi: Universitas Muhammadiyah Sukabumi.

Sari, dkk. 2015. Pengaruh Efektifitas Sistem Pengendalian Internal, Ketaatan Aturan Akuntansi, Persepsi Kesesuaian Kompensasi Dan Implementasi Good Governance Terhadap Kecenderungan Fraud. e-Journal S1 Ak Universitas Pendidikan Ganesha. Volume 3, No.1.

Sudarmo, M. M., T. Sawardi, A., \& Agus Yulianto, Ak., M. A. 2009. Fraud auditing. Bogor: Pusat Pendidikan Dan Pelatihan Pengawasan Badan Pengawasan Keuangan Dan Pembangunan.

Sugiyono. 2018. Metode Penelitian Kualitatif, Kuantitatif Dan R\&D. Bandung: Alfabeta.

Tuanakotta, Theodorus M. 2014. Audit Berbasis ISA (International Standards on Auditing. Jakarta : Salemba Empat.

Tunggal, Amin Widjaja. 2014. Internal Audit, Enterprise Risk Management dan Corporate Governance. Jakarta: Harvarindo. 